\section{Gastric outlet obstruction caused by intramural duodenal pseudocysts in a young man with acute pancreatitis}

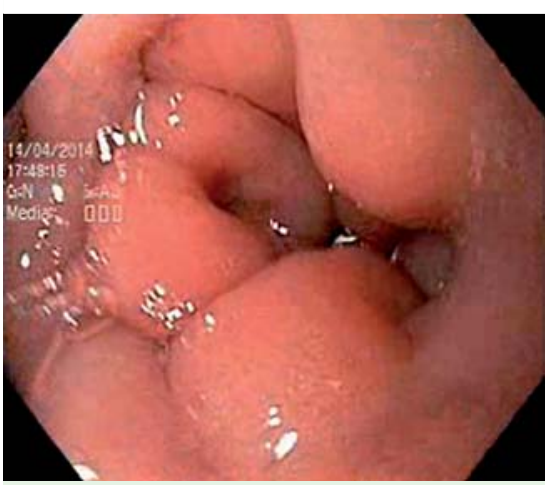

Fig. 1 Endoscopy image showing thickened folds in the second part of the duodenum in a 25-year-old man diagnosed as having gallstoneinduced acute pancreatitis and a 1-month history of recurrent vomiting.

A 25-year-old man presented with abdominal pain. He was diagnosed as having gallstone-induced acute pancreatitis. He improved in a few days and was discharged, but was readmitted 1 month later with a history of recurrent vomiting.

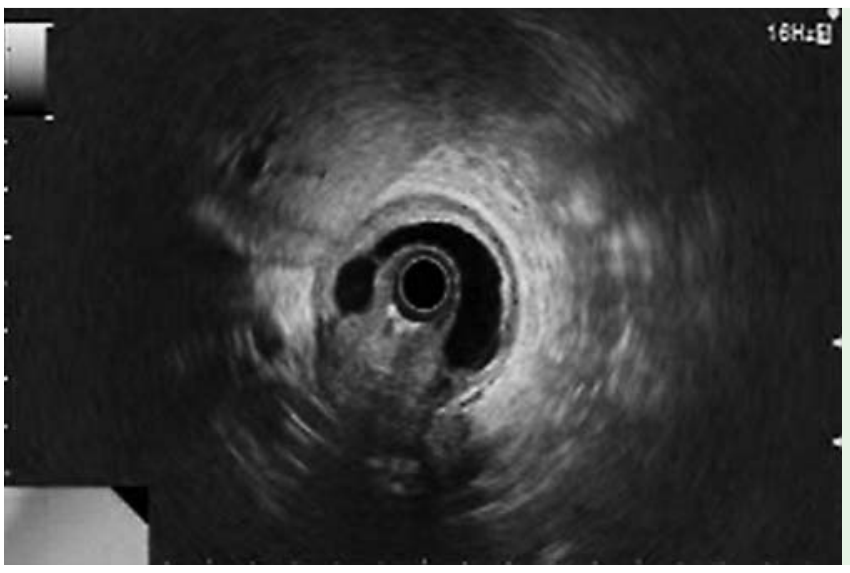

An abdominal ultrasound was negative for any collection. A gastroscopy was performed and showed thickened duodenal walls in the second part of the duodenum with luminal narrowing ( Fig. 1). Endoscopic ultrasound was carried out and showed two intramural cysts in the duodenal wall ( $\bullet$ Fig.2) and heterogeneous pancreatic parenchyma. These cysts were aspirated, and fluid amylase was $31766 \mathrm{U} / \mathrm{L}$ confirming a diagnosis of intramural pseudocyst secondary to an earlier episode of acute pancreatitis. The patient improved after aspiration of the cysts and there was no recurrence of symptoms at 3-month follow-up.

Intramural duodenal pseudocysts are very rare and should be considered in a differential diagnosis of gastric outlet obstruction after acute pancreatitis. As these cysts are small, abdominal ultrasound may not detect them as occurred in our patient. The second part of the duodenum is the most commonly affected site as it is near the head of the pancreas, but intra-

Fig. 2 Endoscopic ultrasound image showing two intramural cysts in the duodenal wall. mural cysts have also been reported in the stomach and esophagus [1,2]. Cysts may develop between the muscularis propria and mucosa or serosa [2,3]. Onethird of cases may have associated extramural pseudocysts [2]. The differential diagnosis includes duodenal duplication cyst and choledochocele [2].

Endoscopy_UCTN_Code_CCL_1AF_2AD

\section{Competing interests: None}

\section{Narendra Singh Choudhary, Rajesh Puri, Randhir Sud}

Institute of Digestive and Hepatobiliary Sciences, Medanta, The Medicity, Gurgaon, Haryana, India

\section{References}

1 Rana SS, Bhasin DK, Rao C et al. Gastric outlet obstruction caused by duodenal intramural pseudocyst. Ann Gastroenterol 2013; 26: 71

2 Rana SS, Bhasin DK, Rao C et al. Intramural pseudocysts of the upper gastrointestinal tract. Endosc Ultrasound 2013; 2: 194-198

3 McCowin MJ, Federle MP. Computed tomography of pancreatic pseudocysts of the duodenum. Am J Roentgenol 1985; 145: 1003 1007

\section{Bibliography}

DoI http://dx.doi.org/

$10.1055 / \mathrm{s}-0034-1390721$

Endoscopy 2015; 47: E58

(c) Georg Thieme Verlag KG

Stuttgart · New York

ISSN 0013-726X

Corresponding author
Rajesh Puri
Medanta
The Medicity
Sector 38
Gurgaon
Haryana
PIN 122001
India
Fax:+91-124-4834111
purirajesh69@gmail.com

